\title{
CONSIDERACIONES DESDE LA FILOSOFÍA PARA FORTALECER LA ETNOGRAFÍA VIRTUAL APLICADA AL DISENO EN TIEMPOS DE LA POSVERDAD
}

Donoso-Cisternas, Sergio; Molina-Serrano, Rafael; Vielma-Laguna, Mitzi

CONSIDERACIONES DESDE LA FILOSOFÍA PARA FORTALECER LA ETNOGRAFÍA VIRTUAL APLICADA AL DISEÑO EN TIEMPOS DE LA POSVERDAD

Revista Legado de Arquitectura y Diseño, vol. 15, núm. 27, 2020

Universidad Autónoma del Estado de México, México

Disponible en: http://www.redalyc.org/articulo.oa?id=477963263003

Esta obra está bajo una Licencia Creative Commons Atribución-NoComercial-SinDerivar 4.0 Internacional. 


\title{
CONSIDERACIONES DESDE LA FILOSOFÍA PARA FORTALECER LA ETNOGRAFÍA VIRTUAL

\author{
APLICADA AL DISEÑO EN \\ TIEMPOS DE LA POSVERDAD
}

\author{
CONSIDERATIONS FROM PHILOSOPHY TO \\ STRENGTHEN VIRTUAL ETHNOGRAPHY APPLIED \\ TO DESIGN IN TIMES OF POST-TRUTH
}

\author{
Sergio Donoso-Cisternas sergiodonoso@uchilefau.cl \\ Universidad de Chile, Chile \\ Rafael Molina-Serrano rafael.molina@uv.cl \\ Universidad de Valparaíso, Chile \\ Mitzi Vielma-Laguna mitzivielma@gmail.com \\ Universidad de Chile, Chile
}

Revista Legado de Arquitectura y Diseño, vol. 15 , núm. 27, 2020

Universidad Autónoma del Estado de México, México

Recepción: 24 Agosto 2019 Aprobación: 27 Noviembre 2019

Redalyc: http://www.redalyc.org/ articulo.oa?id=477963263003
Resumen: La abundancia de información y la llamada democracia de las redes ha facilitado la libre circulación de ideas a nivel global, pero también ha ayudado a inundar la red con mentiras de todo tipo. La paradoja es que muchas de ellas son creídas y asumidas como ciertas, aun sabiendo que son falsas, solamente porque es social o políticamente correcto creer en ellas. Entonces, si los métodos etnográficos, aplicados a la investigación de campo que realiza el Diseño Industrial cuando el campo es virtual, buscan conocer los niveles de acuerdo con las opiniones y no el grado de verdad ¿Puede el Diseño aceptar las mentiras con tal de satisfacer a los usuarios? ¿Cuáles son los posibles límites éticos de seguir mentiras y rumores?

Pareciera que la postura ética es lo único que permite a un profesional discriminar si al proyectar sólo está cediendo a las presiones sociales influenciadas por mentiras. Sin embargo, en este escenario, donde la ética misma está en cuestión, debiese revalorizarse toda la filosofía, pues fortalece el discurso y la trascendencia a los productos más allá de la funcionalidad, es decir, del comportamiento.

El presente trabajo revisa fuentes secundarias acerca de la posverdad y sus implicancias para el Diseño Industrial y pretende poner en discusión algunas de las variables actuales más controversiales que afectan la concepción de productos y servicios. Éstas, a nuestro juicio, se han mostrado como realidades emergentes e ineludibles en tiempos recientes, cuyos efectos están influyendo en la fenomenología del Diseño.

Palabras clave: Diseño, ética, etnografía, métodos cualitativos, postverdad.

Abstract: The abundance of information and the so-called network democracy has facilitated the free movement of ideas globally but has also helped flood the network with lies of all kinds. The paradox is that many of them are believed and assumed as true, even though they are false, just because it is socially or politically correcting to believe in them. So, if the ethnographic methods, applied to the field research carried out by the Industrial Design, seek to know the levels of agreement about opinions and not the degree of truth, can the Design accept the lies in order to satisfy users? What are the possible ethical limits of following lies and rumors?

It seems that the ethical position is the only thing that allows a professional to discriminate if he is only yielding to social pressures influenced by lies. However, in this scenario where ethics itself is in question, philosophy should be revalued because it strengthens discourse and transcendence to products beyond functionality, that is, behavior. 
This paper reviews secondary sources about post-truth and its implications for Industrial Design and aims to discuss some of the most controversial current variables that affect the conception of products and services. These, in our opinion, have been shown as emergent and inescapable realities in recent times and whose effects are influencing the phenomenology of Design.

Keywords: post-truth, ethnography, qualitative methods, design, ethics.

\section{INTRODUCCIÓN}

La manera de propagar ideas en la red es conocida como viral

y esto ayuda a entender cómo las mentiras son distribuidas y que,

\section{APELANDO A LA EMOCIONALIDAD, COMPITEN CON LA VERDAD EPISTÉMICA, AQUELLA ORIGINADA EN LA EVIDENCIA Y NO EN LOS ACUERDOS.}

La irrupción e influencia de internet jamás fue predicha por los futurólogos, quienes visionaban un futuro donde las tecnologías físicas, en un territorio también físico, serían los grandes agentes de cambio. Sin embargo, fue su creación lo que originó una nueva biosfera, conocida como Noosfera (Wilson, 2017), que se constituyó en el nuevo territorio evolutivo o aquel espacio artificial donde habitan las ideas de la cuarta evolución humana.

Es así, como lo virtual se transforma en el mayor vehículo de ideas que, con alcance global, ayuda a la generación de comunidades basadas en la construcción colectiva de nuevas culturas; volubles, cambiantes y en tiempo real (Bauman, 2009). Esto plantea grandes desafíos al Diseño cuando se aplican los métodos etnográficos tradicionales para conocer a las personas y su comportamiento en sociedad, pues el campo de la posverdad es virtual y extraterritorial, y el objeto de estudio, que es el lenguaje, porta "verdades" construidas y aceptadas, aún no siendo ciertas.

La manera de propagar ideas en la red es conocida como viral y esto ayuda a entender cómo las mentiras son distribuidas y que, apelando a la emocionalidad, compiten con la verdad epistémica, aquella originada en la evidencia y no en los acuerdos. Considerando que un virus sólo busca prevalecer a costa de la existencia de la célula, lo viral también podría ser nefasto.

¿Pero qué sucede cuando los observadores sostienen y creen en dos "verdades" antagónicas y eligen una de ellas para interpretar o interactuar con el otro, según quién sea? ¿Qué ocurre en la red con las personalidades anónimas, libres para expresarse sin temor a represalias? ¿Cómo afectan estos hechos sociales al Diseño?

Se ha revisado documentalmente el contexto de la virtualidad y algunas implicancias para el Diseño de la llamada posverdad a fin de poner en discusión cómo el método etnográfico tradicional, aplicado por el Diseño, puede levantar información falsa y colocar a prueba la postura ética, estética y lógica de la disciplina. 


\section{LA POSVERDAD}

"Doblepensar", "crimental”, "policía del pensamiento" (Orwell, 2014), términos acuñados por George Orwell en su novela de anticipación 1984, apelan a una visión del futuro de una sociedad sometida a un gobierno totalitario. Si bien, la historia del siglo XX no transcurrió de esa manera, mucho de lo que visionó está sucediendo, aunque en formas distintas y, donde "doblepensar" es un concepto útil para entender la idea de la posverdad. Este se refiere al hecho de creer deliberadamente en mentiras sabiendo que lo son porque sólo es conveniente creer en ellas. Es así como las personas conscientemente pueden sustentar simultáneamente dos argumentos contradictorios; mentiras sobre las que finalmente se cree y que al ser socialmente aceptadas pasan a la historia construyendo nuevas verdades. Incluso más, negando conscientemente aquello que se sabe que es cierto de manera inequívoca o peor aún, negando aquello que se ve o incluso que se ha constatado personalmente, sin generar mayores conflictos en la moral personal.

Desde el Diseño, este fenómeno se puede extrapolar al trabajo en equipo, donde, al subdividir el trabajo no existe una autoría clara sobre el producto final y se establece una suerte de irresponsabilidad moral (Flusser, 1999) que da origen a productos aberrantes, cuya responsabilidad de uso se transfiere al usuario; ejemplos hay bastantes y muchos de ellos flotan en el Océano Pacífico.

Primero Gramsci y luego Freire, entre otros, identificaron tres grandes factores que articulan el control social; la ignorancia, la educación y la censura (Freire, 2018), donde la ignorancia es el mecanismo de control político y la censura el control de la moral. El control total o hegemonía es ejercida por algún sistema de creencias basadas en lo sobrenatural y el control del estado se fundamenta en la hegemonía de una ideología. Participan también, los medios de comunicación masivos y la educación, que ayudan a sostener y defender un sistema de creencias moralmente aceptable y auto construido. Este sistema de acuerdos sustenta la "infoesfera" como fuente de paradigmas de pensamiento y elaboración de estereotipos (Lewandowsky et al., 2017), que eventualmente la hacen intolerante a los "otros", quienes suelen ser el enemigo externo. La cohesión social también se produce entonces en función del miedo y con esos "otros" se genera competencia por la hegemonía a través del suprematismo y la segregación. Siempre existe la necesidad de crear un "otro", distinto y antagónico (Costa et al., 2011), culpable de todos los desastres que afectan al sistema y que es necesario suprimir para lograr la libertad, sin embargo, el aumento de seguridad va aparejado de una disminución de la libertad, hecho que es aceptado libremente en tanto el enemigo es mayor y más poderoso.

Últimamente son los medios masivos en internet, quienes han sido vehículos de odio y reivindicaciones de todo tipo (De Keersmaecker \& Roets, 2017), donde los enemigos pueden estar personificados, por ejemplo, en los inmigrantes que "atentan" contra la pureza de la cultura o las minorías sexuales que supuestamente "destruyen" las bases de la 
moral, pasado por todo tipo de amenazas reales o imaginarias. Se puede decir que las "dobles morales", que tanto se critica en las redes, han pasado a ser la nueva moneda de cambio de las sociedades, donde las personas son espectadores activos de todo tipo de injusticias y "asesinatos de imagen”, sabiendo que lo son, pero que resulta atractivo al ver cómo lo privado se transforma en un espectáculo público (Sibilia, 2008), sólo por la exacerbación del morbo.

Durante la última década se ha visto cómo la elaboración de noticias falsas (De Keersmaecker \& Roets, 2017) se ha transformado en un nuevo tipo de instrumento de control político. En efecto, ante cualquier hecho político (Antonakaki et al., 2017), ya es habitual ver innumerables cuentas falsas en las redes, muchas de estas creadas por agencias comunicacionales pagadas, desde donde se lanzan calumnias de todo tipo o advertencias de un caos casi apocalíptico en el caso de optar por la propuesta antagónica (ver caso Cambridge Analytica). Publicar una mentira o divulgar un rumor (Gabriels \& De Backer, 2016), por las redes y luego eliminarla, aduciendo un "error involuntario" y pidiendo disculpas, no hace sino instalar el tema y minar la credibilidad del otro, que a su vez no tiene con quién debatir ni a quién responderle, debido a esto, siempre estará en cuestión su integridad moral aun cuando sea inocente de todo.

La crisis de credibilidad de las instituciones se debe en parte a la destrucción del espacio público a causa de los medios de comunicación (Flusser, 1999) y al permanente cuestionamiento hacia las personas que las componen, acerca de su idoneidad moral, desde la perspectiva de una moral ideal. Esta doble moral, no es algo nuevo, la diferencia es que ahora es la masa anónima de las redes quienes construyen estereotipos reduccionistas de la realidad como instrumentos de dominio en las llamadas "sociedades del control" (Deleuze, 2012). Se exige una moral impoluta, que casi nadie posee, pero que se cobra a quienes detenten cualquier grado de autoridad, desde el presidente de la república hasta un profesor, por ejemplo.

Todo esto plantea la necesidad de cuestionar si los métodos de investigación del Diseño son capaces de identificar estas problemáticas o si el propio diseñador o diseñadora, desde la sola postura ética, son capaces de hacerlo.

\section{Todo esto plantea la necesidad de cuestionar
SI LOS MÉTODOS DE INVESTIGACIÓN DEL DISEÑO \\ SON CAPACES DE IDENTIFICAR ESTAS PROBLEMÁTICAS \\ O SI EL PROPIO DISEÑADOR ODISEÑADORA, DESDE LA SOLA POSTURA ÉTICA, SON CAPACES DE HACERLO.}

\section{ETNOGRAFÍAS EN EL CIBER ESPACIO}

Son muchos los elementos que interactúan en un sistema social y la complejidad particular en cada uno de ellos dependen de la percepción de la realidad que opera desde el inconsciente personal y colectivo (Jung, 2015). Esto afecta la toma de decisiones de Diseño debido a los nuevos 
modos de organización social (Bauman, 2009), ya que los métodos de investigación cualitativos no han sido suficientemente adaptados a esta nueva realidad.

La comprensión de los fenómenos sociales, desde una perspectiva holística, considera que lo complejo es inherente a los sistemas pensantes, porque son libres (Donoso, 2019). De ahí surge lo paradójico para el Diseño, a pesar de que las personas perciban la realidad de distinta manera y piensen distinto son capaces de llegar a acuerdos e incluso de crear mitos, ideologías o creencias compartidas.

La estructura de acuerdos construye el sistema de valores, que dan sentido de pertenencia a un grupo, y a su vez, se construyen como una narrativa centrada en las historias comunes en el territorio compartido. Es en este último punto donde han surgido los grandes cambios paradigmáticos en tiempos recientes; el nacimiento de las comunidades extraterritoriales o ciber comunidades (Hine, 2004). En rigor, la manera en cómo se relacionan y establecen vínculos humanos en ellas es igual a la de cualquier comunidad, solo que no está geolocalizada y su lugar está en el ciberespacio donde las relaciones entre los individuos hasta ahora son audiovisuales (Pink et al., 2016). El computador es el instrumento de mediación y socialización (Pizzaleo \& Morcellini, 2002) o incluso de control. Sin embargo, la naturaleza gregaria de las personas las induce a buscar en otras personas sus mismos valores para vivenciar las creencias y juicios que reducen la complejidad y la incertidumbre ante la realidad.

La investigación desde el Diseño debe identificar cómo los individuos adhieren a una cultura y aceptan libremente los valores éticos y morales que les permiten estar en el grupo y que además actúan como una guía o norma para preservar el orden de la sociedad. Las ciber comunidades más radicales se organizan consuetudinariamente en internet bajo una moral compartida, en donde el disenso de opinión suele solucionarse "bloqueando heurísticamente" al otro o mediante campañas de "baneo" agresivas, que permiten mantener la forma y estructura del grupo.

Para el Diseño realizar ciber etnografías sigue por tanto el mismo curso y criterios que se aplican al método etnográfico tradicional, pues operan los mismos fenómenos, pero esta vez sobre sujetos con algunas particularidades; ahora se visionan imágenes y personajes, pero no necesariamente personas mostrando su real identidad (Boellstrorff $e t$ al., 2012). Desde este punto de vista, queda más clara la distinción, las dificultades y los desafíos que debe enfrentar el diseñador que explora lo virtual y que consiste en no saber cuándo observa identidades y cuándo imágenes. La identidad es lo connatural y consciente de cada persona que la diferencia del resto, pero, por otra parte, la imagen es un constructo funcional que se adapta a las circunstancias y a consecuencia de ello una persona puede y de hecho las tiene, muchas imágenes que son usadas para interactuar en sociedad.

Ahora bien, cómo una imagen puede ser construida, el anonimato de las redes permite a las personas construirse una que puede ser confundida fácilmente con la construcción de una nueva identidad (Bauman, 2009). Este nuevo nacimiento, ahora a lo "virtual", borra todo vestigio de las 
frustraciones y deseos en lo "real" y permite realizar y explorar todos aquellos aspectos que no se han podido expresar por las más diversas razones. La imagen creada para ser transmitida no busca el encuentro, sino más bien la propia subsistencia y es de esta manera como surgen estas identidades múltiples (Pizzaleo \& Morcellini, 2002), que a su vez se integran con otras identidades múltiples en comunidades de interés, donde todas las relaciones, siendo ciertas, no son necesariamente sinceras.

El anonimato en la red, por otra parte, garantiza un máximo de expresión y socialización a un mínimo de riesgo, donde muchas personas se crean vidas ideales e incluso se erigen como supervisores morales del resto sin asumir ninguna responsabilidad (Pizzaleo \& Morcellini, 2002). Más aún, no son pocas las personas que mantienen varias imágenes virtuales en la misma comunidad, que asumen distintos roles, en una suerte de desdoblamiento de la personalidad.

\section{EL LENGUAJE COMO OBJETO DE ESTUDIO DEL DISEÑO}

El lenguaje en el sentido amplio es aquello que reduce la complejidad, donde el lenguaje mismo es un objeto de estudio en la investigación del Diseño, pues la codificación de una parte de la realidad en un sistema de acuerdos, articulan la estructura del sistema social. La necesidad de codificación a través del lenguaje es necesaria para disminuir la interpretación y mantener la forma del sistema, mediante códigos consensuados (Berger \& Luckmann, 2014), a fin de transmitir un mensaje socialmente aceptable. De esta manera, un diseñador puede "leer" los sistemas humanos y entender que la complejidad puede no ser infinita, porque las estructuras sociales se comportan casi siempre según las normas que definen. Por otra parte, para la etnografía no importa si los acuerdos sor verdaderos o falsos, lo realmente importante para ella es que existan y que hayan nacido de la propia estructura, sin embargo, en el Diseño se produce una disyuntiva ética, pues estos pueden ser nocivos, aunque para el grupo sean verdaderos y correctos.

El Diseño se enfrenta a la complejidad de la diversidad cultural, donde muchas visiones aparentemente reales, interactúan a través del lenguaje para construir sistemas culturales que construyen sus realidades, que a su vez se encuentran con otros sistemas culturales, que poseen las suyas y entre estas realidades se produce disenso o consenso. Esto no es otra cosa que el sistema de creencias que el grupo asume como verdades e incluso como dogmas de fe, haciendo que las personas crean en ellos sin cuestionarlos, sólo como una manera de recibir afecto y reforzar el sentido de pertenencia.

En la novela 1984, el "Ministerio de la verdad" tenía como una de sus funciones, la creación de la "Nuevalengua", el nuevo idioma elaborado por el partido, donde se fusionaban palabras para crear pequeñas unidades semánticas prepensadas. El trabajo consistía en eliminar palabras, sobre todo los sinónimos, porque ¿Para qué tener tantas palabras que significan lo mismo? Entre sus tareas también estaba la eliminación de los adjetivos 
para lograr una comunicación más precisa y luego eliminar los verbos a fin de reducir las acciones a lo mínimo necesario. De esta manera, las personas sólo podían disponer de un rango muy estrecho de palabras para expresar sus emociones e intereses, disponibles de una "paleta" autorizada por el partido; esto recuerda a los emoticones y su gama de expresiones preconcebidas. Es así como la pobreza del lenguaje se traducía en la práctica en un instrumento de control, conscientemente asumida por el pueblo, pues era la forma de protección que el partido prometía ante los enemigos externos. De manera análoga, el efecto del uso irreflexivo de los emoticones ha llevado a una comunicación fragmentaria y breve (Pizzaleo \& Morcellini, 2002), basada en "tips" y "rankings"; un lenguaje envasado y estereotípico que reduce la emocionalidad, pero aumenta la velocidad. La comunicación se hace cada vez más sintética, superficial y tendiente a lo monosilábico donde se escribe poco y fonéticamente; "1313 ;-), tqm, Tb, xохо. LOL".

Como sea, es una evolución del lenguaje, pero que trae aparejada una simplificación de la complejidad de la condición humana. Este reduccionismo en lo humano necesariamente lleva al fundamentalismo y casi siempre termina en la falsa dicotomía de "si no estás conmigo, estás contra de mí" y esto es algo que ya se ha visto como resultado de la "esloganización" (Freire, 2018) del pensamiento, global e instantáneo (Pizzaleo \& Morcellini, 2002). Un diseñador debe entender que el comportamiento con base en eslóganes implica acciones estimuladas por unidades semánticas ideológicas que transmiten ideas, también preconcebidas y conocidas como "memes".

\section{LA REPLICACIÓN Y PROPAGACIÓN CULTURAL}

Hace décadas que se ha validado a la etnografía y a los métodos derivados de ella como útiles para el Diseño, pues permiten una aproximación más comprensiva a la realidad humana, al contrario de lo que ocurre con los métodos positivistas. En efecto, el experimento del método científico carece de sentido para el estudio de lo humano, por dos razones; la gente miente y también cambia de opinión, pues es sensible a la información que recibe.

La Memética es una metáfora que permite entender el comportamiento de los grupos humanos desde el punto de vista de la evolución cultural (Dawkins, 2017). Según la Memética, la evolución humana no es fruto sólo de una evolución genética, basada en un proceso de selección natural (Dawkins, 2017). La visión genetista no puede explicar la evolución cultural, ni la creación de religiones, ni ningún tipo de manifestación superflua para la sobrevivencia de la especie. Este paralelo con la genética se basa en la existencia de supuestos genes culturales, llamados "memes", que son la mínima unidad semántica capaz de transmitir una idea. Ellos son capaces de replicarse, mutar, almacenarse $\mathrm{y}$ al igual que los virus, propagarse transmitiendo las ideas, de mente en mente, mediante señales (Aunger, 2004). 
Esto tiene diversas implicancias para el Diseño y dado que como metáfora se origina en la teoría de Darwin, sugiere además que una cultura más fuerte sobrevive y "devora” a las más débiles (Dennet, 2015). Si trasladamos la metáfora al ámbito de las marcas, por ejemplo, es posible ver cómo existen algunas que sólo buscan transmitir ciertos mensajes sin portar nada del usuario, es decir, es sólo una transmisión unidireccional con fines comerciales, pero también existe la "fertilización cruzada" (Conti \& Simonelli, 2005) como una nueva posibilidad virtuosa para la co-creación desde el Diseño.

Entonces para el Diseño, en el estudio del comportamiento gregario de las personas en la red, la metáfora de la Memética ayuda a explicar cómo el conocimiento es trasmitido, acumulado y replicado, lo que al final es el elemento ideológico que porta la identidad de una cultura y le permite reproducirse, propagarse y prevalecer. La cultura, entonces, se construye por la información transmitida entre miembros con iguales intereses, ya sea por aprendizaje social mediante la imitación, por la enseñanza o por asimilación (Aunger, 2004).

Las modas y tendencias son promovidas por unidades semánticas replicantes que provocan conductas que son adquiridas por imitación y que luego son trasmitidas en la forma de ideas, una melodía, un eslogan, una religión e incluso virus informáticos, entre otros (Aunger, 2004).

Aquello que se transmite de mente en mente (Aunger, 2004) y que identifica a una determinada cultura, no es la identidad, es una imagen y esto es válido tanto para una persona como para un país. Desde el Diseño, es sabido que una imagen es la manifestación técnica distinta a la identidad, porque es una construcción instrumental que busca comunicar una idea y reducir lo interpretativo de ella. Cuando el Diseño interviene en proyectos de posicionamiento de marketing cultural, por ejemplo (Severino, 2005), el resultado no busca el diálogo intercultural, al contrario, lo que se persigue es que la otra cultura la imite y finalmente consuma sus productos; entonces, el proyecto de Diseño adquiere una carga de proselitismo.

\section{LO BUENO, LO BELLO Y LO VERDADERO}

La trinidad pitagórica consideraba lo bello, verdadero y bueno, como lo virtuoso de la condición humana, en contraposición a lo feo, lo falso y lo malo. Es así como la ética estudia lo bueno y lo malo, la estética lo bello y lo feo, la lógica lo verdadero y lo falso, este conjunto de disciplinas se conoce como la filosofía y es quien formula preguntas humanas.

La ética es un resultado de la historia (Zátonyi, 2002) y en consecuencia de las costumbres, las ideologías y la moral cambiante, donde lo bueno y lo malo son relativos y, en consecuencia, las reglas que dan forma la sociedad también lo son. Entonces, el Diseño tiene una vinculación con la historia y con el contexto, pues lo bello y lo feo depende de la sensibilidad, condicionada por el sistema de valores. En cualquier caso, la estética del Diseño va más allá del goce sensorial y debe ser medida, pues es una función del producto y el Diseño es una disciplina paramétrica. 
Sin embargo, todos los objetos y en especial aquellos diseñados, son portadores de información repetible, pues entre sus dimensiones proyectuales están la simbólica y la utilitaria. La primera asociada a la estética y lo bello, la segunda asociada a lo bueno o utilitario, es decir, a la ética, la moral y el comportamiento, incluyendo la lógica, es decir, lo verdadero, lo falso y lo dudoso. Estos aspectos filosóficos, ubicuos y preeminentes, pero discutibles en la sociedad de la información, son causales en la generación de satisfactores y placer instantáneo, donde lo falso también puede ser verosímil (Bodei, 2008).

La bienal de Arquitectura de Venecia, ya en el año 2000 proclamaba la necesidad de más ética y menos estética, en un reclamo político para repensar las ciudades del futuro, sin embargo, este llamado no era para dejar fuera a la estética, sino más bien para llegar a un equilibrio entre ambas. Si bien, esto también afecta al Diseño, esta dicotomía es incompleta sin la intervención de la lógica.

Una distinción del Diseño como disciplina de las humanidades, implica la teorización de las experiencias, quienes abren el camino a la creatividad. La creatividad evita que seamos sujetos pasivos de la realidad (Zátonyi, 2002). La imposición social de comportarse uniformemente sólo permite la reproducción y no la creación. Es fácil asirse a los dogmas y difícil hacerlo a un sistema libre que promueva la creatividad y en este caso, la estética es analítica y crítica de la opinión impuesta. La estética estudia el fenómeno expresivo entre el sujeto y el objeto, donde la intuición es independiente del conocimiento intelectual (Croce, 1962), sin embargo, expresión y conocimiento son indivisibles.

Lo bello y lo feo son parte de la estética y no pueden existir definiciones unívocas (Bodei, 2008), que se impongan a la percepción y al gusto, pues la estética es ambigua y no normativa. Lo feo impresiona tanto como lo bello (Saint Girons, 2013) y lo feo se asocia a lo vergonzoso y lo torpe (Bodei, 2008).

\section{CONCLUSIONES}

La estética no es privativa sólo del arte, también afecta a las artes mecánicas,

donde se encuentra el Diseño, sin embargo, no es posible dimensionar

\section{LAS ESFERAS DE INFLUENCIA DEL DISEÑO SIN CONSIDERAR A LA FILOSOFIAA EN SU CONJUNTO COMO UNA CLAVE DE LECTURA DE LO HUMANO.}

Seguramente, ninguna de estas consideraciones sería tan importante para el Diseño si no viviéremos en una sociedad global, donde la producción y transmisión de ideas son algunas de las bases del desarrollo humano actual.

La estética no es privativa sólo del arte, también afecta a las artes mecánicas, donde se encuentra el Diseño, sin embargo, no es posible dimensionar las esferas de influencia del Diseño sin considerar a la filosofía en su conjunto como una clave de lectura de lo humano. 
El mercado es una reducción del comportamiento al intercambio económico de bienes y servicios, que se origina en lo social y que depende de los acuerdos. Sabemos que el marketing, mediante la investigación cualitativa, también busca conocer el nivel de acuerdo y no el grado de verdad de las ideas que sustentan una comunidad, pues de esta manera se construye un mercado. La observación etnográfica ayuda elaborar las condiciones de diseño de un producto, en tanto el marketing las dimensiona para evaluar si los hallazgos son o no un negocio interesante. Pero si los acuerdos nacen sobre la replicación de mentiras, finalmente el producto diseñado podría ser una falacia; ideológicamente correcto, pero éticamente reprochable.

Recientemente, han cobrado protagonismo las diferencias culturales y los estilos de vida por sobre las ideologías, que se han erigido como barreras defensivas en contra de otras culturas que se consideran invasoras. Se ha visto cómo la resistencia de las minorías a la "invasión cultural” ha terminado en movimientos de escépticos o indignados y en una violencia reaccionaria, muchas de ellas basadas en mentiras, como, por ejemplo, los movimientos "antivacunas" o los "terraplanistas. Una propagación viral de mentiras es en el fondo una infección cultural, donde el llamado "Diseño por fertilización cruzada" podría ser otro instrumento de control social o pensando positivo, una oportunidad para co-crear. El Diseño, desafortunadamente puede llegar a ser un vector de propagación de infecciones culturales, amplificadas exponencialmente por el manejo de los medios.

La replicación puede ser dañina si la relación establecida con el usuario es parasitaria o puede ser benéfica si fuese cooperativa. Sin embargo, lo viral tiene como único propósito la replicación parasitaria y, en consecuencia, se podría considerar que la comunicación viral al final es nociva. Este momento da la opción al individuo moderno de volverse un ser histórico, que es capaz de superar el parasitismo y transformarse en un actor de cambio.

Una consideración desde la lógica implica reconocer que lo "falso" se origina de dos maneras; el error y la mentira, la primera involuntaria y la segunda consciente. Depende de cada profesional del Diseño optar y actuar en consecuencia, no desde la falacia sino más bien desde lo ético, lo estético y lo lógico, para así pasar de lo subjetivo personal al espacio de la intersubjetivo de la alteridad, para generar nuevos conocimientos y nuevas curiosidades. La posverdad en su espacio virtual nos ha pasado por encima y sólo ahora nos hemos dado cuenta de las implicancias disciplinarias, pues los temas que antes ni siquiera existían, ahora son gravitantes. Puesto que la funcionalidad de los artefactos afecta el comportamiento y en consecuencia es parte de la ética, este momento constituye una oportunidad invaluable para repensar la práctica proyectual y actualizar los métodos de investigación del Diseño en la virtualidad. Sin embargo, en la posverdad son los aspectos éticos quienes se hacen discutibles y en, en consecuencia, se abre el espacio para el discurso amplio acerca de lo bueno, verdadero y lo bello; quizá fortalecer la formación filosófica sea una buena hoja de ruta para la navegación del Diseño en estos tiempos líquidos. 


\section{FUENTES DE CONSULTA}

Antonakaki D., Spiliotopoulos D., Samaras C.V., Pratikakis P., Ioannidis S., Fragopoulou, P. (2017), "Social media analysis during political turbulence”, PLOS One, vol. 12, núm. 10, pp. 1-23.

Aunger, R. (2004), El meme eléctrico, Paidós, Barcelona.

Bauman, Z. (2009), Modernidad líquida, $11^{\mathrm{a}}$ reimpresión ed. Fondo de Cultura Económica, México.

Berger, P. \& Luckmann, T. (2014), La construcción social de la realidad, Amorrortu, Buenos Aires.

Bodei, R. (2008), La forma de lo bello. 2 ed., Machado Libros, Madrid.

Boellstrorff, T., Nardi, B., Pearce, C. \& Taylor, T. (2012), Etnography and virtual worlds, Princeton University Press, Princceton.

Conti, G. \& Simonelli, G. (2005), Fashion \& Design: Cross Fertilization for Innovation within the Italian Fashion System. Chennai, International Conference Innovation and New Product (Goods and Services).

Costa, P., Pérez, J. \& Tropea, F. (2011), Tribus urbanas, Paidós, Buenos Aires.

Croce, B. (1962), Estética, 10 ed., Nueva visión, Buenos Aires.

Dawkins, R, (2017), El gen egoista, 15 ed., Bruño, Madrid.

De Keersmaecker, J. \& Roets, A. (2017), "Fake news": Incorrect but hard to correct. The role of cognitive ability on the impact of false information on social impression. Intelligence, Issue 65, pp. 107-110.

Deleuze, G. (2012), Polis en linea. Available at: http:// journals.openedition.org/polis/5509, acceso 16 agosto 2019.

Dennet, D. (2015), La peligrosa idea de Darwi, 16 ed., Galaxia Gutemberg, Barcelona.

Donoso, S. (2019), Investigación cualitativa para diseño y artes, Ocholibros, Santiago.

Flusser, V. (1999), Filosofía del Diseño, Síntesis, Madrid.

Freire, P. (2018), Pedagogía del oprimido, Universidad Tecnológica Metropolitana, Santiago.

Gabriels, K. \& De Backer, C. (2016), Virtual, gossip:how gossip regulates moral life in virtual worlds, Computers in Human Behavior, Issue 63, pp. 683-693.

Hine, C. (2004), Etnografía virtual, UOC, Barcelona.

Jung, C. (2015), Arquetipos e inconsciente colectivo, Paidós, Buenos Aires.

Lewandowsky, S., Ecker, U. \& Cook, J, (2017), "Beyond misinformation: Understanding and coping with the "post-Truth" era", Journal of Applied Research in Memory and Cognition, vol. 6, núm. 4, pp. 353-369.

Orwell, G. (2014), 1984, Lumen, Buenos Aires.

Pink, S., Horst, H., Postill, J., Hjorth, L., Lewis, T., Tacchi (2016), Digital ethnography. Principles and Practice, Sage, London.

Pizzaleo, A. \& Morcellini, M. (2002), Net Sociology. Interazioni tra scienze sociali e Internet, Guerrini, Milano.

Saint Girons, B. (2013), El acto estético, LOM, Santiago.

Severino, F. (2005), Un marketing per la cultura, Franco Angeli, Milano. 
Sibilia, P. (2008), La intimidad como espectáculo, Fondo de Cultura Económica, Buenos Aires.

Wilson, A. (2017), "Biosphere, Noosphere, Infosphere: Epistemo-Aesthetics and The Age Of Big Data", Parallax, vol. 23, núm. 2, pp. 202-219.

Zátonyi, M. (2002), Una estética del arte y el diseño de imagen y sonido, 5 ed., Nobuko, Buenos Aires. 